\title{
A CASE
}

or

\section{PERFORATING ULCER OF THE ESOPHAGUS,}

\author{
WHICH
}

CAUSED DEATH BY PENETRATING THE AORTA.

BY

WILLIAM HENRY FLOWER, CURATOR to the MidDlesex hospital MUSEUM.

COMMUNICATED BY

CAMPBELL DE MORGAN, Esq.

Received April 15th.-Read June 14th 1853

W. S-, a painter, æt. 51, was admitted into the Middlesex Hospital, under the care of Dr. Hawkins, at 6 p.m., November 19th, 1852. He was a tall, well-made, muscular man ; his countenance death-like ; pulse scarcely perceptible ; extremities cold, and was not conscious when spoken to. It was stated by those who brought him, that he had left his work an hour previously, and was shortly afterwards attacked with profuse hæmorrhage from the mouth, the blood being bright, red, and frothy, immediately after which he fell senseless, and remained in that condition until seen as above described.

On inquiry into his previous history, his son declared that he had been always of very temperate habits ; but for some time past had been desponding, in consequence of having but little work; that a week ago he first complained of a deep-seated pain at the top of the sternum, shooting through to the spine, for which he applied for medical advice, and was said to be somewhat relieved.

The patient was immediately placed in bed; ice was put xxxvi. 
into his mouth, and large doses of acetate of lead administered at frequent intervals, and attempts to bring on reaction used with some success, for on the following morning at 9.30, the pulse was 100, firm and steady, though small. On auscultation, free respiration was heard in every part of the chest, except the upper lobe of the left lung, where the respiratory murmur was deficient, the vocal resonance increased, and there was also some dulness on percussion.

He now stated that he had had a slight cough for many weeks, but without expectoration, and that previous to this attack he was of his usual vigour, and had not lost flesh. At 10 a.m., whilst in the recumbent posture, there suddenly gushed from his mouth upwards of a pint of bright arterial blood, with which was a loose coagulum of the size of a small lemon; while this occurred, the respiration continued unimpeded. Some wine was poured into his mouth, but he was unable to swallow, and a few minutes afterwards he died.

There had been no action of the bowels from the time of his admission, but during the fatal vomiting the bladder involuntarily emptied itself.

My acquaintance with the case having commenced at the post-mortem examination, I am indebted for the above particulars to Mr. Corfe, the Resident Medical Officer at the Hospital.

The body was examined on the 22d of November, fifty-three hours after death; it was found to be well made and muscular, not at all emaciated; the skin was blanched, and the cadaveric rigidity well marked.

On opening the cavity of the thorax, some old adhesions were found at the apices of both lungs; several small crude tubercles in the upper lobe of the left, and the same condition in the right, but to a less degree; the remainder of the lungs were generally normal in appearance, of a pale blueish colour, exsanguine, the anterior margin of both slightly emphysematous; the lining membrane of the trachea and bronchial tubes pale, containing a little mucous froth, not stained with blood.

The heart was full-sized and loaded with fat; the thick- 
ness of the walls and dimensions of cavities normal; the muscular structure apparently healthy; the mitral and tricuspid valves slightly thickened, the semi-lunar valves healthy; no coagula in any of its cavities.

The stomach was large and distended, and when opened was found to contain a clot of blood, which formed an exact cast of the interior of the organ; the mucous membrane healthy in structure, but stained with blood ; round the cardiac orifice were four irregular-shaped patches of erosion, or rather fissures in the mucous membrane, involving partly the stomach, and partly the œsophagus, their longitudinal diameter in the direction of the tube, and varying from 2 to 3 lines in length.

In the mucous membrane of the esophagus, 3 inches above the cardiac orifice, on the left side, was a perfectly circular opening, $3 \frac{1}{2}$ lines in diameter, with slightly elevated edges, which were sharp and clean, as if cut out with a punch, and beveled off from within outwards, the mucous membrane being destroyed, to a greater degree than the tissues beneath, in fact, exactly resembling, on a small scale, the circular perforating ulcer so frequently met with in the stomach : this was immediately surrounded by a reddish halo, but the mucous membrane of the œsophagus elsewhere appeared healthy; on the inner surface of the aorta, at the termination of the descending portion of the arch, on the right side, nearly corresponding with the ulcer in the œsophagus; but on rather a higher level, was an irregular opening, about $1 \frac{1}{2}$ lines in width, with ragged edges formed by the projecting and torn lining membrane; extending forwards from this, for a distance of 3 lines, the coats of the aorta were considerably thinner than elsewhere, the lining membrane over this thin portion being, however, continuous and healthy, and transmitting the dark colour of the stained tissues beneath; about half an inch above, was a patch of opaque atheromatous deposit, the centre of which had advanced to calcification; there were also several other small patches of white deposit in other parts of the lining membrane of the aorta. The opening in the aorta and that 
in the cesophagus communicated freely, a probe passing readily from oue to the other; the distance between the inner surface of each tube was 7 lines, the passage between them contained a clot of blood, and was surrounded by loose cellular tissue infiltrated with blood, but presenting no signs of inflammation, or any attempt at adhesion between the vessel and the osophagus.

The duodenum contained a loose coagulum, resembling that in the stomach, the jejunum was pale, empty, and contracted; its lining membrane pale and unstained. The ileum and whole of the large intestines down to the sphincter ani were distended with semi-fluid blood of a perfectly black colour, with scarcely any fæcal matter; the mucous membrane stained, but presenting no trace of inflammation or ulceration; the Peyer's patches and other glands normal. The mesentery and omentum healthy and well loaded with fat; the liver, spleen, and kidneys of natural size, pale, but apparently healthy in structure; all the other organs and tissues healthy and normal.

Cases of communication between the aorta and œsophagus are to be met with in various works on pathological anatomy; most of these have their origin in aneurism of the vessel; others are said to arise from ulcerations of the œsophagus, generally of either a tuberculous or malignant character, or as in one related to me by Mr. Henry, caused by a stricture of the latter organ; but I believe that detailed cases exactly corresponding to the one above described are rare, if not altogether wanting.

From a careful examination of the specimen, and particularly of the character of the two openings, I cannot but conclude that the ulcerative process commenced in the mucous membrane of the esophagus, and spread through the intervening cellular tissue to the aorta, the outer coats of which appear to have been considerably destroyed before the lining membrane gave way. The existence of atheromatous deposits on the interior of the latter vessel, might incline to the supposition that it was here that the lesion originated; but this condition is so frequent in persons 
above the age of 50 , that it may have been only a coincidence, especially as the lining membrane immediately surrounding the opening appears healthy, and there is no appearance of separation of the coats of the artery or dissecting aneurism, which usually occurs after spontaneous laceration of the internal coat. Moreover, the former conclusion is strongly supported by the regular form and sharp and bevelled appearance of the edges of the ulcer in the œsophagus, which are not such as are found in ulcers caused by external influence, but; as before stated, exactly coincide, as does the symptom of constant pain in the part, with those ulcers of apparently spontaneous origin, termed by Cruveilhier the "simple chronic ulcer of the stomach," and by Rokitansky the "perforating gastric ulcer," and respecting which the latter author states "the pyloric half of the stomach is the seat of the ulcer, it occurs in extremely rare cases only at the fundus; this affection may also appear beyond the stomach in the upper transverse portion of the duodenum, but it does not occur in the remaining portion of the intestinal canal." Under the head of lesions of the cesophagus he does not mention the occurrence of any ulcer similar to that above described. Cruveilhier and Carswell give no more information on this subject. Förster, in his recently published 'Manual of Pathological Anatomy,' p. 165, after mentioning various well-known causes of ulceration of the esophagus, says, "moreover, according to Albers, an ulcer occurs in the œsophagus analogous to the perforating ulcer of the stomach (the "simple ulcer of the œesophagus," Albers,) which is situated mostly on the anterior wall, against the bifurcation of the trachea, gradually perforates the coats of the cesophagus, and forms communications with the trachea, pleuræ, mediastina, and aorta, and also causes ulcerations of the lungs."' As it is not stated in which of Albers' works this is to be found, I presume that his 'Atlas of Pathological Anatomy' is referred to, in the letterpress

I Rokitansky's Pathological Anatomy, 'Sydenham Society's Translation, vol. ii, p. 30 . 
to the second part of which, at p. 204, is a detailed description of the "simple ulcer of the œsophagus," which he says follows an exactly similar course to the simple ulcer of the stomach, and must be distinguished from those caused by external pressure, as from tumour, abscess, or aneurism, and from those spreading ulcers which are the consequence of "oesophagostenosis." $\mathrm{He}$ states further, at p. 219, "the spreading of ulcers of the œsophagus into the aorta has been several times observed: Van Doeveren relates the case of an old woman in whose corpse a large ulcer of the cesophagus was found, which had destroyed the wall of the aorta; the rush of blood through the ulcer had been so copious that the stomach was found quite distended with it. Sandifort relates precisely the same observation." Unfortunately, Albers does not connect this statement specially with the simple perforating ulcer which he had previously described; but his cases may have belonged to any other variety, as indeed in the one described and figured by Sandifort, which appears to be the same as that of Van Doeveren; there is a very large and irregular-shaped ulcer, apparently scrofulous, and the tissues around appear to be considerably involved in the disease.

Another important point illustrating the essentially different nature of Albers' cases and the one I have brought before the notice of the Society, is that in the former " $a$ most intimate growing together of the cesophagus with the aorta" is described, whereas in the latter there was no trace of any such adhesion.

In conclusion, I trust that the Society may not think that I have trespassed upon its valuable time in calling attention to a case which, from its unique character, appears to be of great pathological interest, presenting as it does an example of an ulcer of the cesophagus of a kind very rarely met with in that situation, and remarkable for having, without spreading in width, advanced rapidly and deeply through a considerable space of loose cellular tissue, and finally terminated its course by perforating a tissue so little liable to ulceration as the coats of a large artery. 